\title{
Community structure and reproductive biology of bark beetles (Coleoptera: Scolytinae) associated with Macaronesian Euphorbia shrubs
}

\author{
BJARTE H. JORDAL*
}

School of Biological Sciences, University of East Anglia, Norwich, UK

\begin{abstract}
Keywords. Macaronesia, Euphorbia, Scolytinae, bark beetles, component communities, niche partitioning, communal nesting, mating system
\end{abstract}

\begin{abstract}
Dead wood of arborescent Euphorbia plants in the Macaronesian islands and Morocco has a diverse fauna of wood-boring beetles. Thirty-eight species were found in four species groups of Euphorbia, including 29 species of scolytine bark beetles, six species of cossonine weevils, two species of Laemophloeidae and one of Monotomidae. All scolytines (but not cossonines and cucujoids) have narrow host preferences, using only one host group for feeding and reproduction. The number of islands on which each species was found was also limited, resulting in geographically distinct guilds for each Euphorbia host. The majority of species (26) were found on the E. lamarckii species complex, followed by E. balsamifera (13) and the succulents E. canariense (12) and E. echinus (3), while only two species were found on the rare montane species, E. longifolia, in Madeira. Up to six or seven species could be found in a single branch of $E$. lamarckii and $E$. canariense, respectively, but more than half of the plants had fewer than three species. Putative niche partitioning was indicated by the alternative utilization of different tissues in E. balsamifera and different moisture preferences in the succulent E. canariense. Several unusual features of bark beetle reproductive biology were also observed, including infrequent communal nesting and very small broods. Taken together with the phylogenetic, geographical and biological data now available for most species associated with dead Euphorbia, several of the beetle guilds should provide promising model systems for studying of species interactions and community structure.
\end{abstract}

\section{INTRODUCTION}

The Macaronesian islands in the Atlantic Ocean are located west of the African coast, consisting of four main archipelagos, including Cape Verde in the South, the Canary Islands, the Madeiran Islands and the Azores further north (Fig. 1). These islands have an extraordinary endemic flora of woody herbs and shrubs (Bohle et al., 1996; Panero et al., 1999), which provide many unique and unusual resources for herbivorous insects, in particular wood-boring insects. Several endemic insect lineages have taken the evolutionary opportunity offered by these novel resources, forming large clades of closely related species that specialise on different plant parts or closely related host species (e.g. Percy, 2003; Jordal \& Hewitt, 2004; Jordal et al., 2004). Such "ensembles" (sensu Fauth et al., 1996) of closely related species, which share the same or very similar habitats, represent interesting model systems for the studying niche segregation and community structure.

One particularly promising plant-insect model system involves the beetles associated with woody Euphorbia plants on the Macaronesian Islands. This plant genus is taxonomically as well as vegetatively one of the most diverse plant genera worldwide (Seigler, 1994; Webster, 1994), with more than 2000 nominal species. It is also one of the most ubiquitous plant groups on many of the Macaronesian islands, with the largest diversity of species found on the Canary Islands (Bramwell \& Bramwell, 1990). Several arborescent or succulent cactus-like growth forms have evolved multiple times worldwide (Webster, 1994) and the four distinctive groups of potential host plants in Macaronesia are not a monophyletic group, although some are possibly closely related (Molero et al., 2002). The four groups may be classified as follows: cactus-like succulents (E. canariense, $E$. handiensis, E. echinus), arborescent shrubs of the $E$. lamarckii complex (includes E. regis-jubae, E. tuckeyana, E. anachoreta, E. piscatorium, E. bravoana, E. broussoneti, E. atropurpurea), the more fleshy shrubs of $E$. balsamifera and the more tree-like E. longifolia (Table 1). Euphorbia balsamifera can further be distinguished from the three other groups by having less toxic latex (Bramwell \& Bramwell, 1990). The three arborescent groups differ greatly by ITS DNA sequence data (but not at all within the lamarckii group; see Molero et al., 2002).

Previous reports on the entomofauna associated with Euphorbia describe a community dominated by crypturgine and hypoborine bark beetles (Schedl et al., 1959; Israelson, 1972, 1990), with a few other species from the beetle families Monotomidae, Laemophloeidae, Nitidulidae, Cossoninae and Cerambycidae also reported from these host plants (Wollaston, 1862). However, there are no details on the biology of the species, e.g. their abundance or feeding preferences. Common to all woodboring beetle groups is their complete development, from egg to adult, that occurs inside the host plant. Cossonine weevils differ from the scolytine weevils in that females leave the host plant before mating and ovipositing. In sco-

\footnotetext{
* Current address: Museum of Natural History and Archaeology, Norwegian University of Science and Technology, Erling Skakkesgt 42, N-7491 Trondheim, Norway; e-mail: bjarte.jordal@vm.ntnu.no
} 

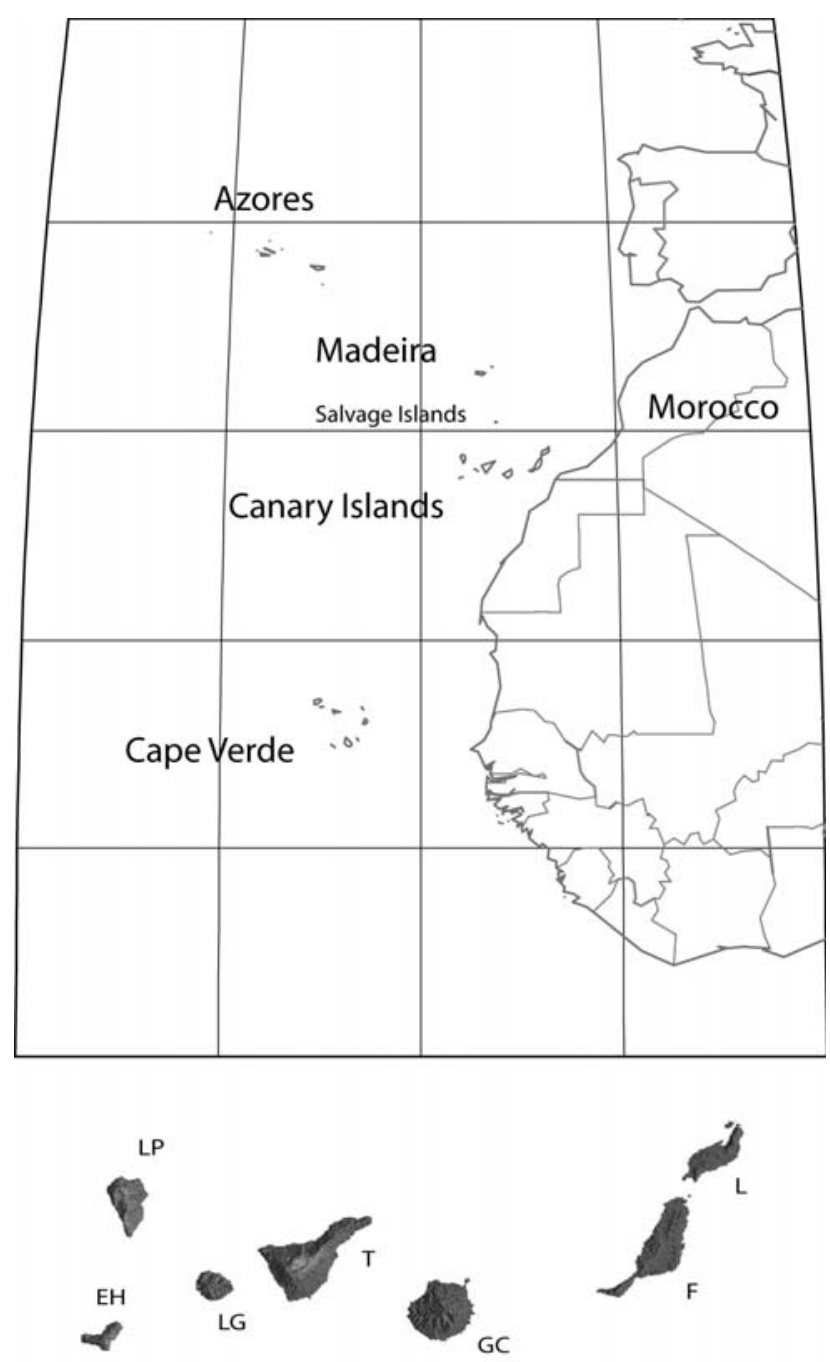

Fig. 1. Map showing the location of the four main Macaronesian archipelagos and the minor Salvage islands. Enlarged view of the seven Canary islands below: El Hierro (EH), La Palma (LP), La Gomera (LG), Tenerife (T), Gran Canaria (GC), Fuerteventura (F), Lanzarote (L).

lytines, and possibly the cucujoid beetles, adults only leave their natal nest when they search for new resources where pairing, mating, egg tunnel construction and feeding take place within various tissues of the new host plant. Hence, dead or moribund plant material serves simultaneously as both a food resource and breeding place for these beetles. Breeding material on a single Euphorbia plant is usually limited to one or a few branches, or bits of branches, at any given time. The rest of the plant consists of live branches that contain latex, which deters or kills beetles, or older dead branches that are too dry for most species. Therefore, plants may be viewed as renewable resources for as long as they live, but colonizing beetles nevertheless can use only very small pieces of wood at any given time and thus the resource is small, discrete and quickly consumed.

Since the pioneering taxonomic work by Wollaston (1862), further details on the taxonomy and morphological variation has been published, in particular for the scolytine bark beetles (Schedl et al., 1959; Israelson, $1972,1990)$ and their geographical distribution is now better known (see Machado \& Oromi, 2000, for the most recent catalogue). However, there are still debates about species that may have been mistakenly reported from some of the islands due to difficulties with species identification. Similarly, several Euphorbia species have been reported as hosts for individual Liparthrum and Aphanarthrum species (Wood \& Bright, 1992), although there was no indication whether successful breeding occurred on all of these plants. Furthermore, recent DNA sequence analyses of the Liparthrum inarmatum complex (Jordal et al., 2004) have provided evidence in favour of cryptic species distinguished primarily by host preference ( $E$. lamarckii vs. E. balsamifera), suggesting high levels of hidden specialisation. DNA sequence data of Macaronesian Aphanarthrum and allies confirms species identities and their distributions (Jordal \& Hewitt, 2004).

Hence, this plant-beetle association provides a very detailed and promising model system for studying community ecology and plant-insect interactions. To further improve our knowledge about the ecology and distribution of the most important members of this Euphorbia guild, host plant records from intensive sampling throughout all the Canary Islands, Morocco, Madeira and Porto Santo, and the Cape Verde islands Sal, Sao Vicente and Santo Antao are presented here. Preliminary data on microhabitat preferences and coexistence patterns are also reported. Breeding of scolytine weevils in large herbs (like those of Euphorbia) is highly unusual as they usually breed in the wood or under the bark of larger trees. Hence, this study also provides new insights into several aspects of the reproductive behaviour of "herbiphage" bark beetles.

\section{MATERIAL AND METHODS}

Beetles from 170 dead or moribund branches and twigs of Euphorbia plants on all Canary Islands, on Madeira and Porto Santo of the Madeira archipelago, on Sal, Santo Antao and Sao Vicente of the Cape Verde archipelago and the Moroccan coast near Agadir were dissected (Table 2). There are no species endemic to single Madeiran or Cape Verde islands and islands within each of these archipelagos were combined. Samples were collected from all parts of an island where the host plant grows. However, it was consistently more difficult to find suitable material of the fleshy arborescent $E$. balsamifera than species of the arborescent E. lamarckii complex. Euphorbia balsamifera does not occur on Madeira, Cape Verde and in Morocco. The cactus-like succulent Euphorbia canariense is missing from these areas and from Lanzarote, and is rare on El Hierro and Fuerteventura. This host plant is replaced by the succulent $E$. echinus in Morocco (related to E. handiensis in Fuerteventura). Usually only one branch (or even only a piece of a branch) is dead on a live plant, but whole dead plants are sometimes available due to drought or human destruction. Beetles collected from one plant (usually a single branch) were a sample and only infested plants were included in the survey. In order to find one plant with suitable dying tissue, an average of 20-50 healthy plants had to be examined.

Collected specimens were compared with type material and other material in the Natural History Museum, London (Wollastons collection) and descriptions in Israelson (1972, 1990). 
TABLE 1. Distribution of Euphorbia host plants. The cactus-like succulents may not be sister species (no molecular data available) but are grouped together based on very similar morphology and tissue structure. All members of the lamarckii, piscatoria and atropurpurea species assemblages are grouped together based on their similar woody tissues, chemistry and near identical ITS DNA sequences. Host plants marked by a "*” were rarely used by beetles and in only three instances was reproduction by Aphanarthrum beetles observed.

\begin{tabular}{|c|c|c|c|c|}
\hline \multicolumn{2}{|c|}{ Species group Species } & \multirow{2}{*}{$\begin{array}{l}\text { Distribution } \\
\text { El Hierro, La Palma, La Gomera, Tenerife, Gran Canaria, Fuerteventura }\end{array}$} & \multirow{2}{*}{$\begin{array}{l}\text { Growth form } \\
\text { cactus-like, large }\end{array}$} & \multirow{2}{*}{$\begin{array}{r}\text { Latex } \\
\text { toxic }\end{array}$} \\
\hline "succulents" & E. canariense & & & \\
\hline & E. echinus & Morocco & cactus-like, small & toxic \\
\hline & E. handiensis & Fuerteventura & cactus-like, small & toxic \\
\hline "balsamifera' & E. balsamifera & All Canary Islands, Northern Africa, Yemen & fleshy shrub & non-toxic \\
\hline "longifolia" & E. longifolia & Montane forests on La Palma, Tenerife, Madeira (very rare) & tall, tree-like & toxic \\
\hline \multirow[t]{8}{*}{ "lamarckii" } & E. lamarckii & El Hierro, La Palma, La Gomera, Tenerife & shrub & toxic \\
\hline & E. regis-jubae & Gran Canaria, Fuerteventura, Lanzarote, Morocco & shrub & toxic \\
\hline & E. piscatorium & Madeira Islands & shrub & toxic \\
\hline & E. tuckeyana & Cape Verde Islands (common only on Santo Antao and Fogo) & shrub & toxic \\
\hline & E. anachoreta & Salvages Islands & shrub & toxic \\
\hline & E. broussoneti $*$ & La Gomera, Tenerife & shrub & toxic \\
\hline & E. atropurpurea* & Teno mountains in Tenerife & shrub & toxic \\
\hline & E. bravoana* & North East La Gomera & shrub & toxic \\
\hline
\end{tabular}

Three species of Aphanarthrum were treated as synonyms as previously reported (Jordal \& Hewitt, 2004): A. saturatum Peyerimhoff and $A$. duongi Villiers (= A. mairei Peyerimhoff) and A. monodi Paulian \& Villiers (= A. armatum Wollaston). Cisurgus resiniferae Peyerimhoff was also treated as a synonym of $\mathrm{C} i$. occidentalis Peyerimhoff.

Mating behaviour was observed using a $12 \times$ hand lens, broods were recorded by carefully removing bark from branches. Broods with only tenerals, or eggs, were not included as these may be incomplete. The sex of colonizing beetles was determined by dissection of genitalia (there is no external dimorphism).

\section{RESULTS}

\section{Species composition and distribution}

Dissection of 170 Euphorbia plants throughout Macaronesia and Morocco resulted in a collection of 38 species of Coleoptera (Table 2). The fauna was largely dominated by various scolytine species: Aphanarthrum (16), Coleobothrus (2), Cisurgus (2), Liparthrum (7) and Triotemnus (1), but the cossonine Mesites fusiformis, the monotomid Europs impressicollis and the laemophloeid Caulonomus rhizophagoides were also collected regularly (Table 2, Fig. 2). Twenty-two of the scolytine species were found in more than one-third of the infested plants
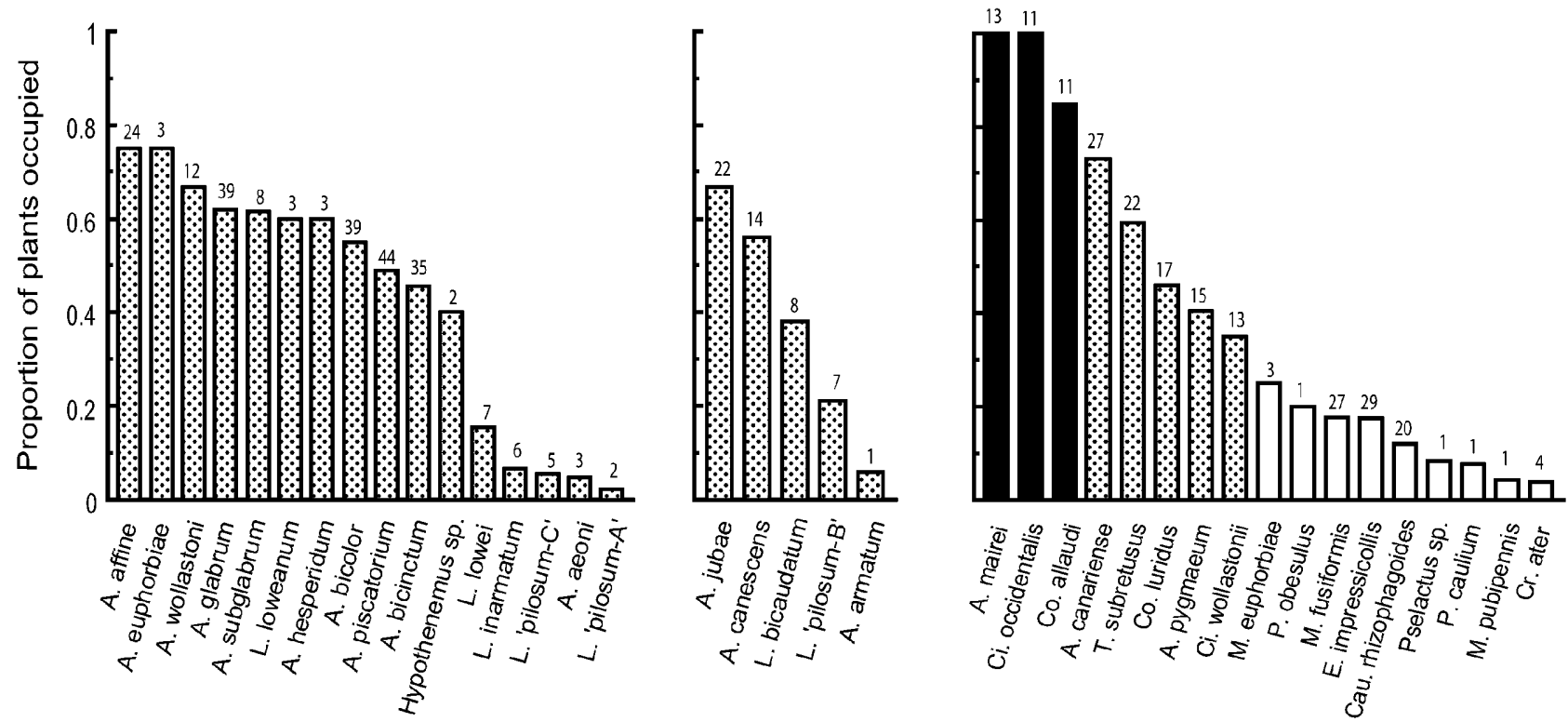

Fig. 2. The proportion of plants occupied by each species within their native distribution. Numbers above each bar indicate sample size. Left, species exclusively associated with host plants of the E. lamarckii complex; middle, species exclusively associated with E. balsamifera; right, species associated with E. echinus (black), E. canariense (grey) and the putative host generalists (in white: cossonines and cucujoids). 


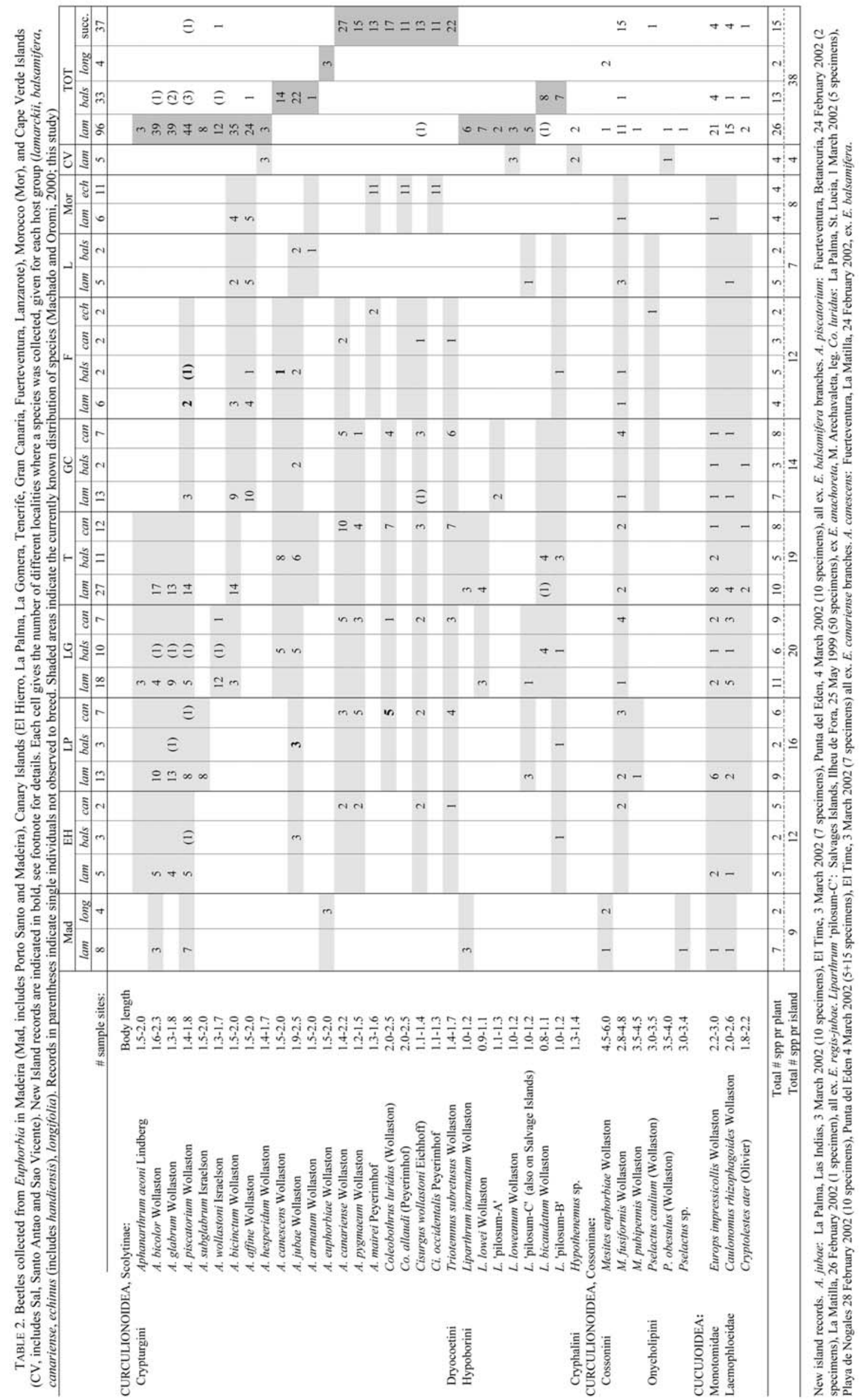




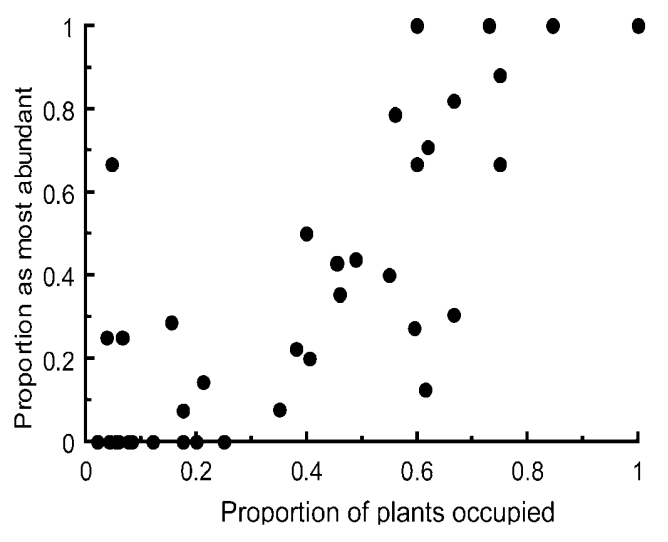

Fig. 3. Relation between the proportion of plants occupied by a species within its native range (x-axis) and the proportion of times being the most abundant species in the sample (y-axis).

within their native range (16 spp. were found in more than $50 \%$ of the plants). Only A. aeoni, A. armatum, some Liparthrum and some of the cossonines were rarely found and in few numbers, even though their euphorb host was common. The most abundant species in any sample were almost always the most frequently collected beetles (Fig. $3)$. Thus the less frequently collected cucujoid and cossonine beetles were always present in low numbers, while most scolytine species were present in larger numbers, with less than $20 \%$ singletons in each of three main host plants (Fig. 4).

Among the frequently collected species, only the cossonine M. fusiformis, and the cucujoids E. impressicollis and $C a$. rhizophagoides colonized the various host groups more or less indifferently (Table 2). The scolytine species, on the other hand, were found in only one host plant, with only two exceptions in 170 samples: $A$. wollastoni was found breeding once in E. canariense, and $A$. affine once in E. balsamifera. Both species breed primarily in hosts of the E. lamarckii complex. Although a few single individuals of Aphanarthrum were collected from one or several of the alternative hosts, they were not recorded as breeding there.

La Gomera and Tenerife were the most diverse islands, for all host plants combined and for each of the Euphorbia host groups. All species that were previously known from these islands (cf. Machado \& Oromi, 2000) were also collected in this study. The geographical distribution of the species followed closely the previously catalogued distribution (Israelson, 1972, 1990; Machado \& Oromi, 2000), with five new island records (A. canescens and A. piscatorium from Fuerteventura, A. jubae and Co. luridus from La Palma and $L$. "pilosum-C" on the Salvages Islands, see Table 2, footnote). Aphanarthrum affine was not found west of Gran Canaria, and all morphologically affine-like specimens in La Gomera were $A$. wollastoni based on DNA sequence data (Jordal \& Hewitt, 2004) and the structure of their genitalia (see also Israelson, 1972).

Considerable overlap was detected in the faunal composition of the E. lamarckii community between islands, but the degree of overlap decreased with distance
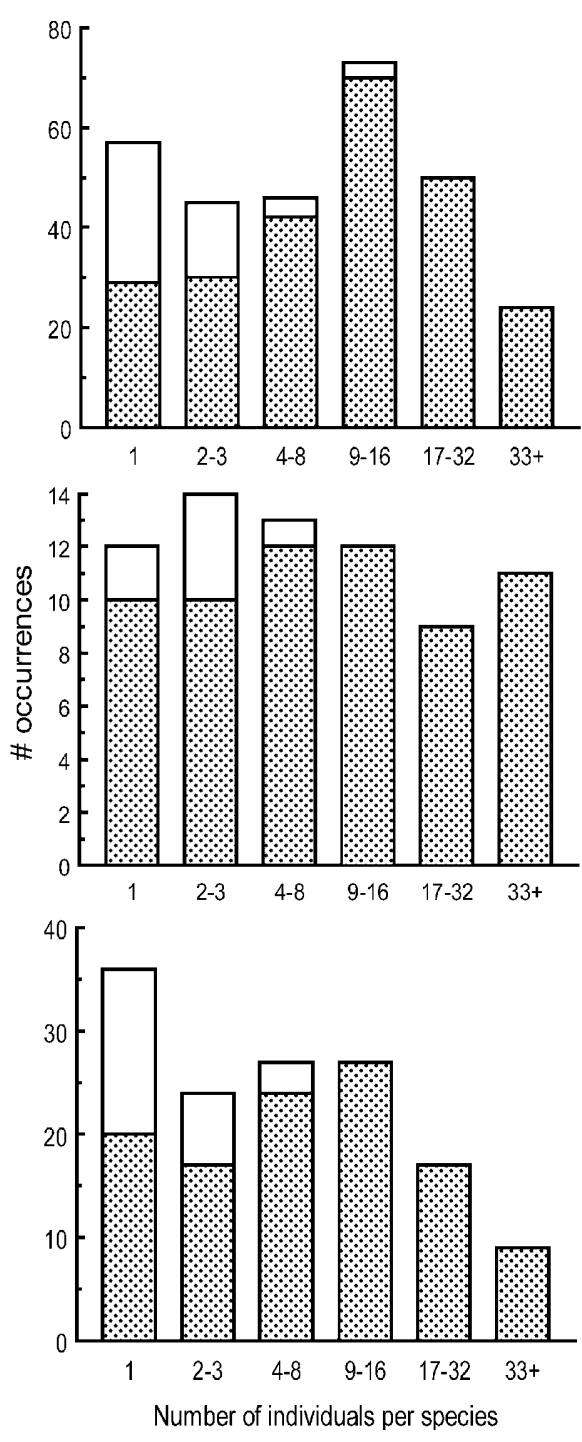

Fig. 4. Distribution of abundances of species per individual host plant. Grey signify Scolytinae, white Cossoninae and Cucujoidea. Top, E. lamarckii complex; middle, E. balsamifera; bottom, E. canariense. Note the high frequency of singletons of cossonine and cucujoid beetles.

between islands (Table 3). However, the community in the four westernmost islands of the Canary archipelago had stronger affiliations with the equivalent community on Madeira than on the three eastern islands Gran Canaria, Lanzarote and Fuerteventura (and Morocco). The Cape Verde islands did not share any species with the other Macaronesian Islands. Species in the E. canariense associated community were less endemic, with most species found on nearly all islands where this host plant grows (cf. Table 2). It should be noted, however, that there was no overlap in species composition with that on the other succulent host plant growing in Fuerteventura and Morocco, E. echinus. No consistent pattern in faunal similarity was observed in the more species poor E. balsamifera community.

Two or more species were usually found together in the same piece of wood, although single species were fre- 
TABLE 3A. Faunal similarity (Jaccard's Index) between islands for beetles associated with host plants of the $E$. lamarckii species complex.

\begin{tabular}{lccccccccc}
\hline & EH & LP & LG & T & GC & F & L & Mor & CV \\
\hline Mad & 0.50 & 0.33 & 0.29 & 0.42 & 0.27 & 0.10 & 0.09 & 0.10 & 0 \\
EH & - & 0.38 & 0.45 & 0.50 & 0.40 & 0.13 & 0.11 & 0.13 & 0 \\
LP & & - & 0.54 & 0.46 & 0.33 & 0.18 & 0.27 & 0.17 & 0 \\
LG & & & - & 0.62 & 0.38 & 0.25 & 0.33 & 0.25 & 0 \\
T & & & & - & 0.42 & 0.21 & 0.25 & 0.27 & 0 \\
GC & & & & & - & 0.57 & 0.5 & 0.5 & 0 \\
F & & & & & & - & 0.5 & 0.6 & 0 \\
L & & & & & & & - & 0.5 & 0 \\
Mor & & & & & & & & - & 0 \\
\hline
\end{tabular}

TABLE 3B. Faunal similarity (Jaccard's Index) between islands for beetles associated with E. balsamifera.

\begin{tabular}{lcccccc}
\hline & LP & LG & T & GC & F & L \\
\hline EH & 1.00 & 0.33 & 0.40 & 0.25 & 0.40 & 0.33 \\
LP & - & 0.33 & 0.40 & 0.25 & 0.40 & 0.33 \\
LG & & - & 0.83 & 0.29 & 0.38 & 0.14 \\
T & & & - & 0.33 & 0.43 & 0.17 \\
GC & & & & - & 0.14 & 0.25 \\
F & & & & & - & 0.17 \\
\hline
\end{tabular}

TABLE 3C. Faunal similarity (Jaccard's Index) between islands for beetles associated with E. canariense.

\begin{tabular}{lccccc}
\hline & LP & LG & T & GC & F \\
\hline EH & 0.45 & 0.56 & 0.63 & 0.63 & 0.60 \\
LP & - & 0.66 & 0.75 & 0.75 & 0.50 \\
LG & & - & 0.70 & 0.89 & 0.33 \\
T & & & - & 0.33 & 0.38 \\
GC & & & & - & 0.38 \\
\hline
\end{tabular}

quently encountered (Fig. 5). When several species occurred together they were most often closely related species of Aphanarthrum and other crypturgine genera, with individual egg tunnels and larval mines intersecting each other. The highest within-unit species diversity was found in E. canariense and E. lamarckii, with a maximum of six or seven species, respectively. Euphorbia balsamifera had on average a much lower herbivore diversity, with no more than four beetle species present in one plant. Pairwise comparisons of species co-occurrence showed that no particular pair of species was reciprocally excluded over all sites (not shown). However, $A$. bicinctum was often the only species of Aphanarthrum found when this species was collected on La Gomera and Tenerife and was found considerably less often together with A. bicolor, A. glabrum and A. piscatorium on those islands, than with $A$. affine on Gran Canaria, Fuerteventura and Lanzarote. Similarly, T. subretusus was found less often together with Co. luridus and $A$. pygmaeum than with $A$. canariense, in $E$. canariense.

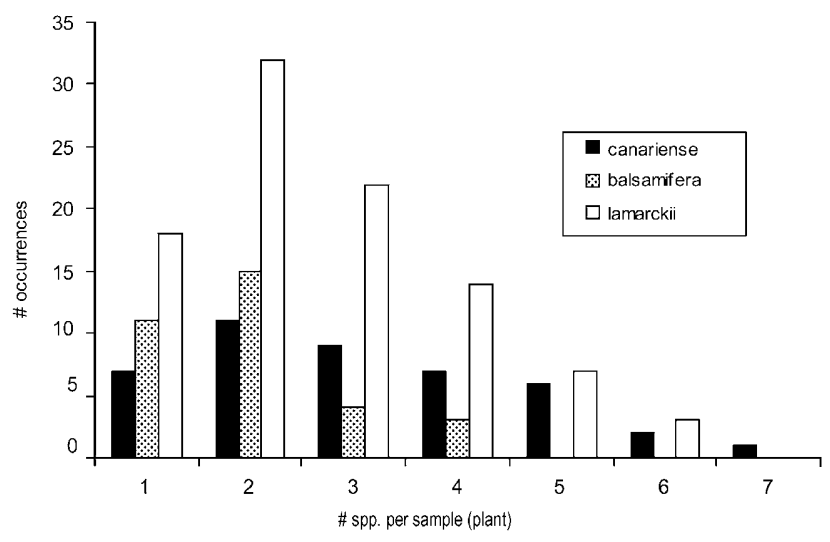

Fig. 5. Distribution of the number of beetle species per plant, for each Euphorbia host group. Counts include all groups of beetles from the Canary Islands (except Lanzarote where $E$. canariense is absent). The same pattern was found when only scolytine beetles were included.

In addition to narrow host-plant preferences, further division of the resource may occur in E. canariense and E. balsamifera. Aphanarthrum jubae and A. canescens preferred different parts of the latter host plant, with $A$. jubae mostly in thicker branches, although breeding in the thin terminal twigs that leads to the inflorescence was also observed (Table 4). Aphanarthrum canescens was almost entirely found in recently dead, or dying, soft, terminal twigs. Comparing only those plants where both species were found, tissue preferences were significantly different from an independent tissue-selection distribution (Chi-square test: $p=0.024$ ).

On E. canariense, differences in moisture preference were found between Co. luridus and T. subretusus. As this spurge ages it loses water and becomes leathery and ultimately dry and hard. Triotemnus subretusus was rarely found colonizing this host in its early stages of desiccation, and all broods were found in very dry and hard tissue (Fig. 6). Only once was Co. luridus taken from such dry host plants. This kind of ecological differentiation was not observed in species breeding in the succulent euphorbs in Morocco (E. echinus), where all three species (A. mairei, Co. allaudi, Ci. occidentalis) co-occurred in both moist and drier material at every site examined. Species of Liparthrum usually preferred very old and dry twigs where species of Aphanarthrum were not found, but one third of the records for Liparthrum were from fresh or soft tissues.

Table 4. Host tissue selection in $A$. jubae and A. canescens. Terminals were defined as the last segment of a branch to which the inflorescence is attached. The $p$-value gives the probability that tunnel initiation was independent of plant tissue, based on a chi-square distribution $(d f=1)$. Values in brackets indicate counts where both species were present on the same plant.

\begin{tabular}{lcccc}
\hline Species & \multicolumn{2}{c}{ Branches Terminals } & Total & $p$ \\
\hline A. jubae & $18(7)$ & $9(3)$ & $27(10)$ & $0.083 \mathrm{~ns}$ \\
A. canescens & $3(2)$ & $16(8)$ & $19(10)$ & $0.003^{* *}$ \\
Total & $(9)$ & $(11)$ & $(20)$ & $\left(0.024^{*}\right)$ \\
\hline
\end{tabular}




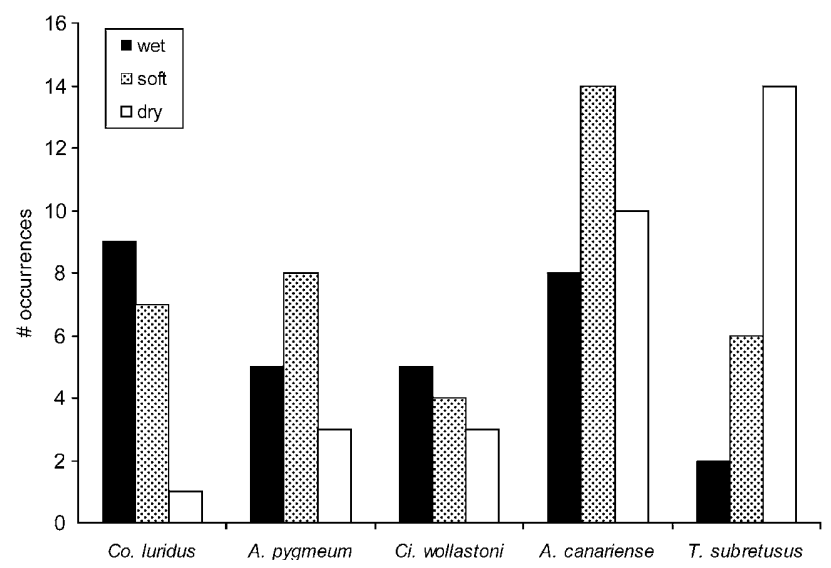

Fig. 6. The frequency of host tissue selection by five species of scolytine bark beetles breeding in dead E. canariense branches in the Canary Islands, based on moisture content (dry, soft, wet).

\section{Reproductive behaviour of the scolytine beetles \\ Communal nesting}

When colonization density was low, egg tunnels were excavated with only one male-female pair present in each egg tunnel. This was always the case in terminal twigs in which Aphanarthrum canescens always formed monogynous pairs $(\mathrm{n}=14)$. However, when colonization densities were higher, as in the thicker branches, multiple male-female pairs were found in the same entrance and main tunnel, forming one large communal breeding system as observed once for each of the species $A$. glabrum (5 pairs), A. wollastoni (8 pairs) and $A$. jubae (19 pairs). In addition to using entrance holes of the same species, several instances of using a different species' entrance holes was also observed: $A$. affine and $A$. piscatorium used new tunnel systems of $A$. jubae $(\mathrm{n}=1)$ and $A$. bicolor $(\mathrm{n}=3)$, respectively, and Liparthrum "pilosum-C" used old tunnels of $A$. affine $(\mathrm{n}=2)$. Note that the later-arriving species in each case was the smaller of the two (see Table 2 for body size). It should also be noted that $A$. bicolor was often the first species to colonize, attacking greenish-yellow tissues, with $A$. glabrum and $A$. piscatorium taking advantage of the reduced latex defence of the plant several days later.

\section{Mating}

Females initiated new tunnels in 34 of 42 instances, in six different Aphanarthrum species (Table 5). Although some individuals were possibly making new tunnels for maturation feeding only, the strong bias towards females indicates that egg tunnels are initiated by the female sex. In $A$. bicinctum, females made new entrance holes (1-2 $\mathrm{mm}$ deep) that covered the head and prothorax and then paused to mate $(n=4)$. Males in each case approached the partly exposed females, positioning their ventral surface against the dorsal surface (elytra) of the females, with their head directed towards the rear of a female and moved their mandibles slowly sideways on her elytral declivity. Thereafter, the male had to turn through 180 degrees to mate with the female while she remained in the
TABLE 5. Identification of the tunnel initiating sex in various species of Aphanarthrum. Each ratio gives the number of females to males that initiated new tunnels in one locality. The third column indicates the island on which each sample was collected.

\begin{tabular}{lccc}
\hline Species & Female : Male & Island samples & Pooled data \\
\hline A. affine & $3: 1,1: 3,2: 0$ & GC, F, Mor & $6: 4$ \\
A. bicinctum & $2: 0$ & LG & $2: 0$ \\
A. bicolor & $6: 0$ & LP & $6: 0$ \\
A. canescens & $1: 0,1: 0$ & $\mathrm{~T}, \mathrm{~T}$ & $2: 0$ \\
A. glabrum & $3: 0,6: 0$ & $\mathrm{LP}, \mathrm{LP}$ & $9: 0$ \\
A. jubae & $3: 0,2: 1,1: 2,3: 1$ & $\mathrm{EH}, \mathrm{T}, \mathrm{L}, \mathrm{L}$ & $9: 4$ \\
\hline All species & & & $34: 8$ \\
\hline
\end{tabular}

same position in the entrance hole. Males were also observed chasing other males before and after mating, possibly they were guarding their female $(n=6)$. Consistent with their ability to mate on the outside of plants, nuptial chambers were not produced by this species or any other species breeding in Euphorbia. However, mating was observed inside the host in Ci. wollastoni $(\mathrm{n}=$ 1) and Co. luridus $(\mathrm{n}=1)$ (both breeding in $E$. canariense), but there was no trace of a nuptial chamber.

\section{Brood development}

Broods were small, with no more than 14 offspring produced by any of the species. Average brood size was much lower, ranging between 4.3 and 9.7 (Table 6). Egg size was large compared to body size in Aphanarthrum and Coleobothrus, with egg length to body length ratios ranging from 0.26 in Co. luridus $(\mathrm{n}=1), 0.32-0.35$ in $A$. glabrum $(\mathrm{n}=2), A$. piscatorium $(\mathrm{n}=2)$ and $A$. jubae $(\mathrm{n}=$ $1)$, to 0.39 in $A$. canescens $(\mathrm{n}=2)$.

Larvae of all the species mined in unpredictable directions, making it difficult to follow the development of tunnels. The larvae of at least one species, A. jubae, moved deep into the wood before pupation $(\mathrm{n}=3)$. During brood development, males leave the nest at unpredictable times, leaving as early as before egg laying in $A$. bicolor $(\mathrm{n}=7)$, or stay until the larvae are well developed or the eclosion of teneral adults in A. hesperidum $(\mathrm{n}=6)$, A. jubae $(\mathrm{n}=2), A$. canescens $(\mathrm{n}=4)$ and L. loweanum $(\mathrm{n}$ $=2$ ). In $A$. jubae, males were also observed to leave before egg laying $(n=3)$ and egg hatch $(n=2)$. Hence, there was no consistent pattern in how long males are staying with the females.

After metamorphosis young adults may leave the nest when their exoskeleton has hardened, or rarely, stay and complete another generation. Successive generations were observed in $A$. piscatorium $(\mathrm{n}=3)$ and $A$. wollastoni $(\mathrm{n}=2)$, where recently started egg tunnels (with pairs and females laying egg) were found in recently dead tissue (no entrance holes) close to the natal brood (in older, dead tissue).

Mortality due to parasitoid wasps was low, with only one wasp found on the 170 plants examined. It was associated with one of the species $T$. subretusus, Co. luridus or A. pygmaeum infesting E. canariense. Some of the 
Table 6. Brood size recorded in nine species of Scolytinae that breed in dead Euphorbia.

\begin{tabular}{llcccc}
\hline Species & Host & Max & Avg. & sd & $\mathrm{N}$ \\
\hline A. canescens & E. balsamifera & 8 & 5.8 & 1.7 & 4 \\
A. jubae & E. balsamifera & 11 & 5.8 & 2.5 & 12 \\
A. bicinctum & E. lamarckii & 14 & 9.7 & 3.8 & 3 \\
A. glabrum & E. lamarckii & 10 & 8.7 & 1.5 & 3 \\
A. piscatorium & E. lamarckii & 9 & 8.0 & 1.0 & 3 \\
A. euphorbiae & E. longifolia & 7 & 6.0 & 1.4 & 2 \\
A. hesperidum & E. tuckeyana & 7 & 5.4 & 1.1 & 5 \\
Co. luridus & E. canariense & 14 & 8.6 & 2.8 & 12 \\
L. loweanum & E. tuckeyana & 5 & 4.3 & 0.6 & 3 \\
\hline
\end{tabular}

cucujoid beetles (E. impressicollis and $\mathrm{Ca}$. rhizophagoides) may also feed on eggs and larvae of the scolytine species in addition to debris produced by other beetles. Cucujoid beetles were present early in the succession of bark beetle broods, possibly reducing the survival of some of the broods. One species of Cleridae was found on 15 occasions on the surface of the plants and may be a common predator of bark beetles in dead Euphorbia.

\section{DISCUSSION}

\section{Regional community structure}

Contrary to previous summaries of host plant records (Schedl et al., 1959; Wood \& Bright, 1992) this study has shown that all scolytine species have distinct preferences for a single Euphorbia host or host group. When stray specimens of a few species were found on a less preferred host they were not reproducing. Hence, it seems likely that previous reports have not discerned between rare and common hosts and the ability to reproduce on these hosts. Furthermore, the extensive overlap in host plant distribution, locally as well as regionally, rejects an alternative hypothesis that species are mistakenly classified as specialists if they use a locally abundant host plant that replace other potential hosts geographically (Stevens, 1986; Kelley \& Farrell, 1998).

Host fidelity is also strong in a historical context, as illustrated by few host switching events in Crypturgini and Hypoborini. Recent phylogenetic analyses of mitochondrial and nuclear DNA sequences and morphology have demonstrated the monophyly of all Aphanarthrum plus Coleobothrus, and that all species of Liparthrum associated with Euphorbia are monophyletic (Jordal \& Hewitt, 2004; Jordal et al., 2004), implying that hostgenus selection is strongly constrained. Switching between the four host groups in Macaronesia is also rare. For instance, there were no switch to other Euphorbia host groups from the two original succulent associations of Cisurgus, Aphanarthrum and Coleobothrus (Jordal \& Hewitt, 2004). A more general utilisation of host plants is seen in some of the cossonines and in the three cucujoid species. The cucujoids do not feed directly on fresh tissue but on the debris produced by other bark beetles.

In contrast to the high fidelity to each Euphorbia host group, there was apparently less specialisation within the
E. lamarckii complex. Aphanarthrum piscatorium, A. bicolor and L. inarmatum were found on E. piscatoria and E. lamarckii on Madeira and the westernmost Canary islands, respectively, and $A$. piscatorium, A. bicinctum and $L$. "pilosum-C" on E. regis-jubae east of Tenerife. However, these host plants are allopatric vicariants of each other, recently evolved, and are not distinguished properly by genetic data (Molero et al., 2002). It would therefore be misleading to define the herbivores that are associated with these allopatric host plants as functionally polyphagous rather than monophagous. Four species of Aphanarthrum, however, used additional sympatric hosts species on La Gomera and Tenerife (E. atropurpurea, E. bravoana, E. broussoneti). However, the relative colonization frequency on these additional host plants was less than $13 \%$ compared to E. lamarckii and thus they may not be natural host plants. The high number of potential hosts on La Gomera and Tenerife could nevertheless have played an historical role in the diversification of beetle species on these islands, as past specialisation on more narrow subsets of host plants may have occurred. However, the number of beetle species on E. balsamifera and $E$. canariense was also highest on these two islands (cf. Table 2), suggesting that geographical components are more important than host plant co-evolution for beetle diversity. Allopatric speciation has been demonstrated for several subspecies complexes in Aphanarthrum that diverged on different islands before dispersing onto neighbouring islands (Jordal \& Hewitt, 2004).

The similar species distributions reported previously (Schedl et al., 1959; Israelson, 1972, 1990; Machado \& Oromi, 2000) and those reported here suggest that species occurrence on specific islands is predictable and stable seasonally and between years. Several authors (Israelson, 1972; Machado \& Oromi, 2000) have questioned the presence of $A$. affine on La Gomera and intensive sampling on this island did not result in the collection of this species. Thus, A. affine only occurs on Gran Canaria, Fuerteventura, Lanzarote and Morocco. The distribution of three undescribed, cryptic species of the L. "pilosum" complex is more uncertain, given that these were all previously included in L. inarmatum. However, two of the species were found on four and five islands, respectively, suggesting wide and overlapping distributions in these sibling species.

\section{Local community structure}

This study has shown that several closely related species of Aphanarthrum frequently occur together along with several less related scolytines and other beetles. If there is a certain regularity in resource availability, and the associated herbivores are effective colonizers of new resources, long-term interactions between the most similar species could potentially be very strong. However, recent progress in our understanding of the forces structuring communities has led to a consensus that the interactions between individuals of the same species are likely to be stronger than those between different species (Shorrocks et al., 1984; Ives \& May, 1985). This is based on observations of non-saturated ecological niches and the 
large variability in species abundances between resource units in the same ecological niche, rendering most species ecologically equivalent in terms of fitness. It is particularly interesting that such aggregation models fit discrete, ephemeral and patchily distributed resources, as demonstrated by another bark beetle guild associated with dead Cecropia petioles (Calabrese \& Kirkendall, in prep.). Similarly, bark beetles in other leaf petiole communities demonstrate considerable departure from equilibrium dynamics, arguing against strong interspecific interactions in this kind of discrete, ephemeral habitat (Beaver, 1979). Intraspecific aggregation was considerable in most samples collected from various Euphorbia hosts in this study (see also Fig. 4) - only 24 of the 170 samples had fewer than 10 colonizing pairs of the most abundant species. Hence it seems likely that intraspecific aggregation is at least as important for the survival of an individual as is the presence or absence of a different species.

However, a few species nevertheless divided the resource more finely into microhabitats, which suggests that some sort of niche partitioning occurs in some species. The clearest example of resource division was found in the two Aphanarthrum species that breed in different parts of E. balsamifera. Aphanarthrum canescens is the only species that apparently specialise on dead, soft, terminal twigs of living shrubs, where $A$. jubae was found only on rare occasions. Further experiments are needed to confirm the ecological significance of the different host tissue preferences shown by species associated with $E$. canariense. However, in six of the seven plants where $T$. subretusus was found together with Co. luridus, the former species was found in much drier tissues, suggesting that moisture preference is an important factor in explaining the low frequency of coexistence of these two species. Thus, late tunnel initiation, or longer development of broods, do not explain the high occurrence of $T$. subretusus in dry E. canariense tissue. Additional cases of niche partitioning may occur, e.g. in E. lamarckii, but were not detectable in this short study.

Finally, we know very little about the historical component of species interactions. However, preliminary data on Liparthrum (see Jordal et al., 2004) and Aphanarthrum (see Jordal \& Hewitt, 2004; Jordal, Emerson \& Hewitt, in prep.) have demonstrated recent introductions to new islands. Genealogical data can be used to identify the most recent member of this community on each island, species that may be an ephemeral component of the local community. For instance, A. piscatorium is a recent arrival on Gran Canaria, Fuerteventura and Madeira; A. bicinctum on La Gomera, A. affine in Morocco and L. inarmatum on Madeira. Thus, the currently high numbers of similar species on the E. lamarckii host group possibly reflects temporal oversaturation of the habitat due to slow or ineffective exclusion of the locally least adapted species.

\section{Unusual breeding behaviour}

Feeding on lignified stems of arborescent Euphorbia shrubs, or fleshy stems of cactus-like succulents, is a highly unusual habit in the weevil subfamily Scolytinae.
Succulent euphorbs are composed of inner lignified tissue and external tissue of transformed fleshy leaves. Hence, these beetles are actually herbiphages in the sense that they feed on derived leaf tissues. Only a few other scolytine groups are known to share similar herbiphage characteristics (Wood, 1982; Wood \& Bright, 1992). The largest such group includes at least six closely related genera in the tribe Dryocoetini, including the genus Triotemnus. All species of Cisurgus breed in small herbs, including the two species found in Euphorbia. Most species of Cactopinus feed and breed in various cacti in North America. In addition, there are isolated examples in Hylastinus and Kissophagus (Hylesinini), Hypothenemus (Cryphalini) and Scolytodes (Ctenophorini). Hardly anything is known about the reproductive ecology of beetles living in this kind of habitat and the data reported here provides an interesting comparison with that of the bark beetles that breed in wood or inner bark.

Monogynous pairing is most likely the rule in Liparthrum, Triotemnus subretusus and most of the crypturgine species, but communal nesting occurred on a few occasions in several species of Aphanarthrum. Promiscuous mating is quite likely under such circumstances, rendering both sexes polygamous. The communal behaviour is rare among most bark beetles, but was previously reported for another crypturgine beetle, Crypturgus pusillus, which breed in conifers (see Kirkendall, 1983). Interestingly, species of the basal crypturgine genus Dolurgus and Crypturgus, are frequently found using the entrance hole of a larger, established species (Schwarz, 1894; Wood, 1982; pers. observ.). Thus, it seems likely that the communal nesting behaviour is derived from a generally inquiline behaviour, a feature also observed in some Aphanarthrum and Liparthrum species. The swift access into an existing entrance hole reduces the apparent predation risk during mate finding and tunnel initiation, which indicate the possible adaptive significance of inquilism and colonial nesting.

The considerable variation in time that a male spends together with the egg laying female is also noteworthy, insofar as very few insects show this kind of variation within a species (Kirkendall, 1983). Although only $A$. jubae provided enough data to infer intraspecific variation, the large variation also between close relatives further indicate that this could also apply to other Aphanarthrum species. Opportunities for extra-pair copulations are many, given the frequently intersecting tunnels made by different families, especially when colonial aggregations occur. Males should therefore be especially prone to leave early when searching for mates occurs on the same plant. Sporadic instances of promiscuous behaviour may also explain why males sometimes guard females.

Perhaps the most unusual feature of reproduction in Euphorbia beetles was the very small brood size in scolytine beetles. Bark beetles that breed in the inner bark of conifers and broadleaved trees usually produce more than 20 eggs, up to 200 eggs in some species (Browne, 1961; Wood, 1982). Broods of close relatives of Aphanarthrum or Liparthrum - the species of Crypturgus associated 
with spruce (see Schwartz, 1894; pers. obs.) and the species Hypoborus ficus associated with fig trees (pers. obs.) - are not much larger than those on Euphorbia species, which may indicate the inherent limitations to brood production in larger clades of species. Further limitations to brood size is possibly the rapid desiccation of thinbranched breeding material, which reduces the number of eggs that can develop before the host plant tissue becomes too dry. On the other hand, eggs laid by Aphanarthrum and Coleobothrus are very large, which possibly compensates for small broods by increasing the survival of each offspring (Jordal \& Kirkendall, 1998).

\section{Concluding remarks}

Based on recent species delineation (Israelson, 1972, 1990; Jordal \& Hewitt, 2004, Jordal et al., 2004), host plant preferences (this paper) and distribution on the Macaronesian islands (Machado \& Oromi, 2000; this paper) it is now possible to define the specific communities for each Euphorbia group, on each island. Taken together with the recently established phylogenies of the crypturgine and hypoborine elements of these communities (Jordal \& Hewitt, 2004, Jordal et al., 2004) and phylogeographical data for several Aphanarthrum species (Jordal, Emerson \& Hewitt, in prep.), it is possible to distinguish recent and perhaps ephemeral evolutionary interactions from those of longer historical duration. The relatively few species involved in each community, and the small broods produced per family, further provide some of the transparency needed to obtain precise data on species abundances. Hence, this is a useful model system for ecological and evolutionary studies on species interactions and the assembly of component communities.

ACKNOWLEDGEMENTS. I would like to thank L. Kirkendall and K. Harkestad for providing samples and information during the initial phase of this project. I am also grateful to P. Oromi for help with logistics and permits, and each of the "Cabildos" in the Canary Islands, for issuing collecting permits. Many thanks also to S. Shute in the Natural History Museum, London, for access to type material in the Wollaston Collection and M. Knížek for assistance with Liparthrum taxonomy. Previous drafts of this paper were greatly improved by R. Beaver, L. Kirkendall, two anonymous reviewers and the language editor. This project was funded by a Marie Curie Fellowship HPMFCT2001-01323.

\section{REFERENCES}

Beaver R.A. 1979: Non-equilibrium "island" communities. A guild of tropical bark beetles. J. Anim. Ecol. 48: 987-1002.

Bohle U., Hilger H.H. \& Martin W.F. 1996: Island colonization and evolution of the insular woody habit in Echium L. (Boraginaceae). Proc. Nat. Acad. Sci. USA 93: 11740-11745.

Bramwell D. \& Bramwell Z.I. 1990: Flores Silvestres de las Islas Canarias. Editorial Rueda, Madrid, 376 pp.

Browne F.G. 1961: The biology of Malayan Scolytidae and Platypodidae. Malay. For. Rec. 22: 1-255.

Fauth J.E., Bernardo J., Camara M., Resetarits W.J., Van BuskiRK J. \& McCollum S.A. 1996: Simplifying the jargon of community ecology: a conceptual approach. Am. Nat. 147: $282-286$.

ISRAELSON G. 1972: Male copulatory organs of Macaronesian species of Aphanarthrum Wollaston. With designations of lectotypes and descriptions of new taxa (Col., Scolytidae). Entomol. Scand. 3: 249-257.

ISRAELSON G. 1990: A key to the Macaronesian Hypoborini, with description of two new species (Coleoptera, Scolytidae). Bocagiana 137: 1-11.

Ives A.R. \& MAY R.M. 1985: Competition within and between species in a patchy environment: relations between microscopic and macroscopic models. J. Theor. Biol. 115: 65-92.

JoRdal B.H. \& HewitT G.M. 2004: The origin and radiation of Macaronesian beetles breeding in Euphorbia: the relative importance of multiple data partitions and population sampling. Syst. Biol. 53: 711-734.

JoRDAL B.H. \& KirKendaLl L.R. 1998: Ecological relationships of a guild of tropical beetles breeding in Cecropia leafstalks in Costa Rica. J. Tropical Ecol. 14: 153-176.

Jordal B.H., Kirkendall L.R. \& Harkestad K. 2004: Phylogeny of a Macaronesian radiation: host-plant use and possible cryptic speciation in Liparthrum bark beetles. Mol. Phylogenet. Evol. 31: 554-571.

Kelley S.T. \& FarRell B.D. 1998: Is specialization a dead end? The phylogeny of host use in Dendroctonus bark beetles (Scolytidae). Evolution 52: 1731-1743.

KiRKENDALl L.R. 1983: The evolution of mating systems in bark and ambrosia beetles (Coleoptera: Scolytidae and Platypodidae). Zool. J. Linn. Soc. 77: 293-352.

Machado A. \& Oromi P. 2000: Elenco de los Coleopteros de las Islas Canarias. Instituto de Estudios Canarios, La Laguna, $306 \mathrm{pp}$.

Molero J., Garnatje T., Rovira A., Garcia-Jacas N. \& SusanNa A. 2002: Karyological evolution and molecular phylogeny in Macaronesian dendroid spurges (Euphorbia subsect. Pachycladae). Plant Syst. Evol. 231: 109-132.

Panero J.L., Francisco-Ortega F., Jansen R.K. \& SantosGuERRA A. 1999: Molecular evidence for multiple origins of woodiness and a New World biogeographic connection of the Macaronesian Island endemic Pericallis (Asteraceae: Senecioneae). Proc. Nat. Acad. Sci. USA 96: 13886-13891.

PeRCY D.M. 2003: Radiation, diversity and host plant interactions among island and continental legume-feeding psyllids. Evolution 57: 2540-2556.

Schedl K.E., Lindberg H. \& Lindberg H. 1959: Coleoptera Insularum Canariensium. II. Scolytidae. Soc. Sci. Fenn., Comm. Biol. 20: 1-78.

Schwarz E.A. 1894: A parasitic scolytid. Proc. Entomol. Soc. Wash. 3: 15-17.

SeIGLER D.S. 1994: Phytochemistry and systematics of the Euphorbiaceae. Ann. Missouri Bot. Garden 81: 380-401.

Shorrocks B., Rosewell J., Edwards K. \& AtKinson W. 1984: Interspecific competition is not a major organizing force in many insect communities. Nature 310: 310-312.

Stevens G. 1986: Dissection of the species-area relationships among wood-boring insects and their host plants. Am. Nat. 128: $35-46$.

Webster G.L. 1994: Classification of the Euphorbiaceae. Ann. Missouri Bot. Garden 81: 3-32.

Wollaston T.V. 1862: On the Euphorbia-infesting Coleoptera of the Canary Islands. Trans. Entomol. Soc. London 1: 136-214.

Wood S.L. 1982: The bark and ambrosia beetles of North and Central America (Coleoptera: Scolytidae), a taxonomic monograph. Gt. Basin Nat. Mem. 6: 1-1359.

Wood S.L. \& BRight D. 1992: A catalog of Scolytidae and Platypodidae (Coleoptera). Part 2: Taxonomic index. Gt. Basin Nat. Mem. 13: 1-1553.

Received January 27, 2005; revised and accepted September 21, 2005 